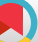

\title{
Production and Purification of Specific IgY Against InvG Protein of Salmonella typhimurium
}

\author{
Mohammad Hasan Jahandar (iD ${ }^{1,2}$, Mohammadreza Nassiri ${ }^{2,3,}{ }^{*}$, Khadijeh Nasiri ${ }^{4}$ and Alireza \\ Haghparast ${ }^{5}$ \\ ${ }^{1}$ Department of Agriculture, Bam Branch, Islamic Azad University, Bam, Iran \\ ${ }^{2}$ Department of Animal Science, Ferdowsi University of Mashhad, Mashhad, Iran \\ ${ }^{3}$ Recombinant Proteins Research Group, Research Institute of Biotechnology, Ferdowsi University of Mashhad, Mashhad, Iran \\ ${ }^{4}$ Department of Exercise Physiology, Faculty of Sport Science, University of Mazandaran, Babolsar, Iran \\ ${ }^{5}$ Department of Veterinary Medicine, Faculty of Veterinary Medicine, Ferdowsi University of Mashhad, Iran \\ Corresponding author: Department of Animal Science, Ferdowsi University of Mashhad, Mashhad, Iran and Recombinant Proteins Research Group, Research Institute of \\ Biotechnology, Ferdowsi University of Mashhad, Mashhad, Iran. Email: nassiryr@um.ac.ir
}

Received 2018 December 16; Revised 2019 February 24; Accepted 2019 February 28.

\begin{abstract}
Background: Salmonella infections are one of the most important causes of human and animal diseases, worldwide. InvG gene is one of the main genes of type III secretion system and leads to initial binding of the bacteria to the host cells. In the recent decades IgY technology has been detected as an efficient alternative procedure to generate antibody for applying in immunotherapy.

Objectives: This research attempted to produce and detect IgY against the recombinant InvG protein of Salmonella typhimurium and evaluate specificity of anti-InvG IgY against the recombinant InvG antigen.

Methods: Polymerase chain reaction was carried out to amplify InvG gene with InvG one pair of specific primer of Salmonella typhimurium. pTZ57R/T and pET32a vectors were used to clone and sub-clone InvG gene. Recombinant pET32a-InvG plasmid was transferred to E. coli BL21 (DE3). Expression induction was carried out using $1.5 \mathrm{mM}$ isopropyl $\beta$-D-1-thiogalactopyranoside. Next, the recombinant InvG protein was injected to laying hens. Western-blotting and Dot-blotting analysis and iELISA were carried out to determine the specify of anti-InvG IgY.

Results: This research produced specific InvG egg yolk antibodies by injecting InvG protein to the hens. The anti-InvG IgY corroborated to bind specifically with the InvG protein of Salmonella typhimurium.

Conclusions: The finding of the present research confirmed that anti-InvG IgY could be suggested as a candidate for passive immunization and protection against Salmonella typhimurium.
\end{abstract}

Keywords: Salmonella typhimurium, InvG gene, Recombinant Protein, Immunization, IgY

\section{Background}

Salmonella enterica are important gram-negative bacteria that are responsible for food-borne disease gastroenteritis and comprises of about 2500 serovars (1). Salmonella can infect warm-blooded animals and humans. Salmonella typhimurium is related to the consumption of contaminated poultry meat and eggs (2). The major pathogenicity islands of Salmonella include SPI1, SPI2, SPI3, SPI3, SPI4, and SPI5. SPI 1 and SPI2 are the most important virulence factors of Salmonella enterica that code type III secretion systems (T3SS-1). The type III secretion system plays an important role in infusion of effector proteins in the cytosol of eukaryotic cells (3). Various parts of the type III secretion system are organized in a supramolecular frame, known as the needle complex (4). It has been reported that SPI1 virulence factor plays a role in the intestine for initiation of inflammatory responses and the invasion of the intestinal epithelium cells (5). Also, the SPI2 virulence factor leads to improvement in Salmonella survival within macrophages and multiplication in phagocytic cells (3). The major genes of SPI1 include invA, invB, invC, invE, invF, invG, invH, hilA, sipA, $\operatorname{sip} C, \operatorname{sip} D, \operatorname{spaR}, \operatorname{org} A, \operatorname{sip} B$, and $\operatorname{sptP}$. The InvG gene located on SPI1 encodes an essential component of the base substructure of the needle complex (4). The InvG gene is one of the primary genes located in the membrane of bacteria and plays a major role in the initial binding of the bacteria to the host cells. There is evidence that InvF and InvG genes of SPI 1 are essential for effective entry of Salmonella to epithelial cells (6). As a result, the invG protein can be suitable as a recombinant protein to stimulate the immune system against Salmonella typhimurium. 
In the recent years, there has been an increasing prevalence of antibiotic-resistant bacteria, which has led traditional antibiotics to become less effective. Oral administration of specific antibodies is an excellent source to protect humans and animals against gastrointestinal pathogens (7). An egg yolk antibody called IgY has been used widely for protection and treatment against infections (8). Several researches have proven that use of IgY is effective as passive protection against infections, such as Enterotoxigenic Escherichia coli, bovine coronavirus, bovine rotavirus, Salmonella, Pseudomonas, and Staphylococcus $(9,10)$. It was reported that IgY (egg yolk immunoglobulin) from immunized chickens is safe, protective, and effective against intestinal infection in human and animals (11).

\section{Objectives}

The current research attempted to produce anti-InvG IgY by immunizing hens with recombinant InvG antigen and investigate the specificity of anti-InvG IgY of Salmonella typhimurium.

\section{Methods}

\subsection{InvG Gene Amplification}

Genomic DNA was extracted from a standard strain of Salmonella typhimurium (ATCC $=14028$ ) (Bioneer, Korea). Oligonucleotide primers containing BamHI and XhoI restriction sites (underlined) were designed using primer 5 software and then primers were synthesized by Macrogen (South Korea). The primer sequences were InvG-Forward:

5'-CGCGGATCCGCGGGCAGACAAATGAAGACACATA-3' and InvG-Reverse:

5'-CCGCTCGAGCGGTTTAATTGCCTCCTGACCTCTAT-3'. Polymerase Chain Reaction was performed in a $25-\mu \mathrm{L}$ volume containing $1.5 \mu \mathrm{L}$ of $\mathrm{MgCl}_{2}$ (50 mM), $2.5 \mu \mathrm{L}$ of $10 \mathrm{X}$ PCR buffer, $2 \mu \mathrm{L}$ of each deoxynucleoside triphosphates, (20 mM), $2 \mu \mathrm{l}$ of mix primer $(10 \mathrm{pmol} / \mu \mathrm{L}), 2 \mu \mathrm{L}$ of DNA template $(50 \mathrm{ng} / \mu \mathrm{L}$ ), and $1.25 \mathrm{U}$ of $P f u$ DNA polymerase and some deionized water. The conditions for InvG gene amplification included denaturation at $94^{\circ} \mathrm{C}$ for six minutes, followed by 32 cycles of denaturation at $94^{\circ} \mathrm{C}$ for 30 seconds, annealing at $58^{\circ} \mathrm{C}$ for 30 seconds and extension at $72^{\circ} \mathrm{C}$ for 45 seconds, and final extension at $72^{\circ} \mathrm{C}$ for 10 minutes.

Ligation reaction of $I n v G$ gene in the $\mathrm{pTZ} 57 \mathrm{R} / \mathrm{T}$ plasmid (Fermentas, Germany) was performed by the T-A clone. The ligation product was transformed in E. coli $\mathrm{DH} 5 \alpha$. Then, transformed cells were selected and the positive bacterial clones were confirmed by restriction enzyme digestion and PCR colony using InvG primers.

\subsection{Expression of the Recombinant InvG Protein}

The plasmids pTZ57R/T-InvG and pET32a were digested using BamHI and XhoI enzymes and purified by the gel DNA recovery kit. The T4 DNA ligase method was used to ligate InvG gene in the pET32a vector $\left(16\right.$ hours at $\left.16^{\circ} \mathrm{C}\right)$. The recombinant pET32a-InvG vector was transformed to E. coli (TOP10F' cell). The transformed cells were grown overnight at $37^{\circ} \mathrm{C}$ on LB agar plates with ampicillin $(100 \mu \mathrm{g} / \mathrm{mL})$. The recombinant pET32a-InvG colonies were analyzed by enzyme digestion (BamHI and XhoI) of the recombinant plasmid and the PCR colony method. The PCR colony was performed with specific oligonucleotides of the InvG gene and pET T7 primers. The recombinant pET32a-InvG vector was sequenced to confirm the integrity open reading frame of the recombinant plasmid.

For expression, the recombinant plasmid was transferred to E. coli BL21(DE3) inoculated in Luria broth culture containing ampicillin with a concentration of $100 \mu \mathrm{g} / \mathrm{mL}$ and grown overnight at $37^{\circ} \mathrm{C}$ in $150 \mathrm{rpm}$. Overall, $50 \mathrm{~mL}$ of fresh LB liquid containing ampicillin $(100 \mu \mathrm{g} / \mathrm{mL})$ was incubated with $5 \mathrm{~mL}$ of pre-culture at $37^{\circ} \mathrm{C}$ in $150 \mathrm{rpm}$ to reach $\mathrm{OD}_{600}: 0.6$. Then, the InvG protein was induced by 1.5 mM IPTG and incubated at $37^{\circ} \mathrm{C}$ for four hours with shaking at $150 \mathrm{rpm}$. After induction, samplers of the recombinant protein were harvested at different time points. The InvG expression was subjected to $12 \%$ SDS-PAGE.

\subsection{Dot-Blotting and Western-Blotting Analysis}

Overall, $2 \mu \mathrm{g} / \mathrm{mL}$ of $6 \mathrm{X}$ his-tagged recombinant InvG protein, PBS as a negative control, and the extract of the transformed bacteria were dotted on the nitrocellulose membrane. It was immersed in $1 \%$ bovine serum albumin and shaken (30 minutes). In the next step, it was washed with PBST. The membrane was immersed in anti-His-tag rabbit diluted at 1:500 (one hour). Next, the membrane was washed with PBST and incubated with anti-rabbit IgG $(\mathrm{H}+\mathrm{L})$ and HRP conjugate (one hour). The membrane was washed with PBST. Color development was detected by addition of 3, 3'-diaminobenzidine dissolved in PBS and $\mathrm{H}_{2} \mathrm{O}_{2}$.

For Western-blotting, the recombinant InvG protein was separated using 12\% SDS-PAGE and transferred on the nitrocellulose membrane. The BSA $1.5 \%(\mathrm{w} / \mathrm{v})$ was used to block sites and incubated at $4^{\circ} \mathrm{C}$ overnight. The membrane was incubated with primary antibody (1:1000). Anti-rabbit IgG conjugated to HRP was applied as the secondary antibody (1:2000). The membrane was placed in peroxidase chromogenic substrate solution (3, 3-diaminobenzidine, Sigma), and dissolved in $\mathrm{H}_{2} \mathrm{O}_{2}$ to stop the color development. 


\subsection{Purification of the Recombinant InvG Protein}

The recombinant InvG protein was purified using Qiagen nickel-nitrilotriacetic acid agarose column (Qiagen, Hilden, Germany). The pellet of the induced cells was resuspended in lysis buffer (10). Overall, $1 \mathrm{mg} / \mathrm{mL}$ of lysozyme was added to the pellet. Then, it was incubated on ice (30 minutes) and disrupted by sonication. In total, $1 \mathrm{~mL}$ of the $50 \% \mathrm{Ni}$-NTA slurry to $10 \mathrm{~mL}$ cleared lysate was shaken at $4{ }^{\circ} \mathrm{C}$ for 60 minutes. The lysate-Ni-NTA mixture was loaded on a column. The recombinant protein was washed. The 6X his-tagged recombinant protein was eluted with elution buffer (10). The InvG protein concentration was determined using the Bradford method (12). Before the hen immunization with the InvG protein, it was dialyzed to remove imidazole and other impurities.

\subsection{Immunization of Hens}

In the initial immunization, the laying hens were inoculated with $200 \mu \mathrm{g}$ of the recombinant InvG protein +200 $\mu$ L of complete Freund's adjuvant (Sigma, USA) through intramuscularly injection. The second and third immunization were followed with a two-week interval and the hens were injected with $200 \mu \mathrm{g}$ of the recombinant InvG +200 $\mu \mathrm{L}$ of incomplete Freund's adjuvant. In the control group, the hens were injected with Freund's complete adjuvant only. Laid eggs were collected daily after the first immunization for ten weeks, and marked and stored at $4{ }^{\circ} \mathrm{C}$.

\subsection{IgY Antibody Purification}

The IgY antibody was purified using polyethylene glycol precipitation procedure (13). The purified IgY was investigated on sodium dodecyl sulphate polyacrylamide gel electrophoresis.

\subsection{Dot-Blotting and Western-Blotting of Anti-InvG IgY}

Dot-blotting and Western-blotting analyses were carried out as described previously (10), only with the difference that the primary antibody was hen anti-InvG IgY.

\subsection{Indirect Enzyme-Linked Immune Sorbent Assay}

Activity of IgY against the InvG protein was specified by iELISA. Overall, $2 \mu \mathrm{g} / \mathrm{mL}$ of the InvG protein diluted in PBS was coated on wells overnight at $4^{\circ} \mathrm{C}$. After three times washing (PBS-Tween), plates were blocked with 1\% BSA (at $37^{\circ} \mathrm{C}$ for 1 hour). Subsequently, $100 \mu \mathrm{L} /$ well of IgY diluted in PBS (1:2000) was added and incubated with $100 \mu \mathrm{L} /$ well of rabbit anti-chicken IgY H\&L (HRP) and diluted in PBS (1:10000) for two hours at $37^{\circ} \mathrm{C}$. The colorimetric detection was performed using O-phenylenediamine (Sigma) and the plate was washed with PBST. The reaction was stopped by the addition $3 \mathrm{M} \mathrm{H}_{2} \mathrm{SO}_{4}$ to the wells. The absorbance was measured at $492 \mathrm{~nm}$.

\subsection{Statistical Analysis}

Statistical analysis was performed using the SPSS 19.0 statistical package (SPSS, Chicago, IL, USA). Differences in mean ELISA titers between weeks were estimated by comparing the means using repeated measures analysis of variance (ANOVA). A P value of less than of 0.05 was considered significant.

\section{Results}

\subsection{Amplification of InvG Gene and Cloning of the InvG Gene}

The coding region of the InvG gene was amplified by PCR(Figure 1A). The purified InvG gene was successfully inserted in the t pTZ57R/T vector to construct the recombinant pTZ57R/T-InvG plasmid. The results of PCR assay with specific primers and restriction enzyme revealed that the InvG gene was correctly inserted in the $\mathrm{pTZ57R/T}$ vector (Figure 1B). Also, colonies of the recombinant pET32a-InvG vector were corroborated with PCR using PET T7 primers (Figure 2A). The existence of the InvG gene in the pET32a vector was corroborated by enzymatic digestion (Figure 2B).

\subsection{Expression and Purification of the Recombinant InvG Pro-} tein

The results of the InvG expression at different time points were indicated on 12\% SDS-PAGE electrophoresis by induction with $1.5 \mathrm{mM} \mathrm{IPTG}$ (Figure 3A). Figure 3 shows that the InvG gene was expressed in E. coli. The recombinant InvG protein could be identified around $81 \mathrm{kDa}$ (pET32 (18.5 $\mathrm{kDa})+$ InvG (62.275 kDa). The result of Western-blotting and Dot-blot analysis verified existence of the recombinant InvG protein (Figure 3B and $\mathrm{C}$ ). The recombinant InvG protein was purified using Ni-NTA agarose column (Figure 4A). The concentration of InvG protein was calculated as 1.52 $\mathrm{mg} / \mathrm{mL}$.

\subsection{Analysis of IgY-InvG}

The IgY antibody was extracted from the egg yolks by PEG precipitation method. The result of IgY was electrophoresed on 12\% SDS-PAGE and indicated that IgY contains two main proteins with a light chain (25 kDa) and heavy chain (65 kDa) (Figure 4B).

\subsection{Dot Blotting and Western Blotting Analyses}

The results revealed that anti-InvG IgY in 1:2000 dilution could detect the recombinant InvG protein. Western blot analysis detected an $81 \mathrm{kDa}$ protein band (Figure 4C). 

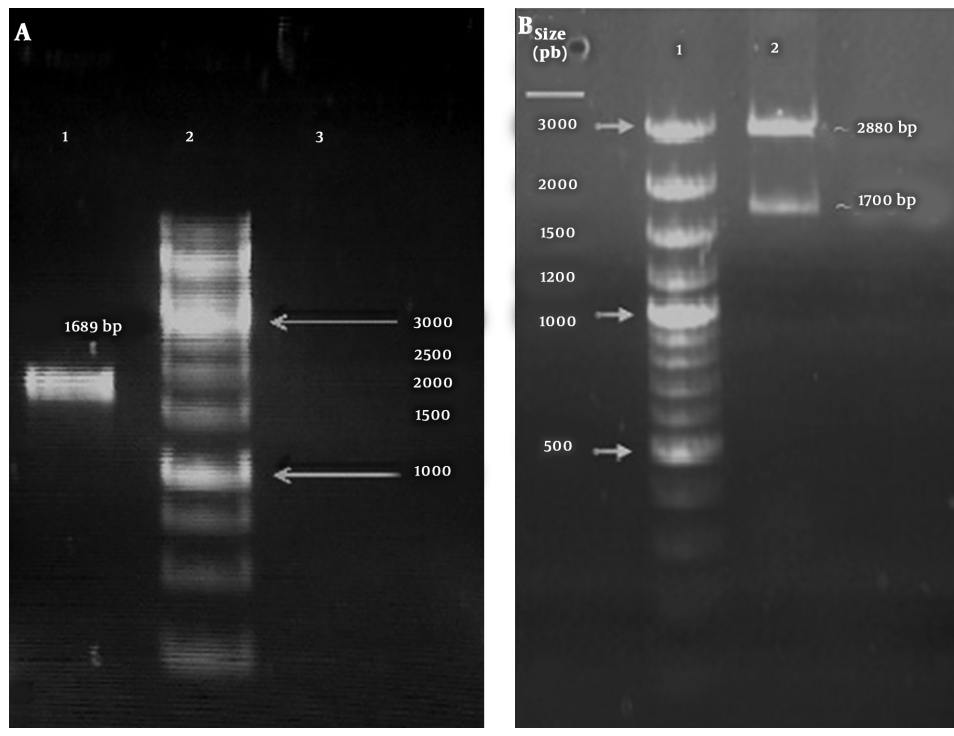

Figure 1. A, electrophoresis of PCR products from InvG gene of Salmonella with specific primers (lane 1: InvG gene, lane 2: DNA size marker, lane 3: negative control). B, digested pTZ57R/T-InvG plasmid, lane 1: DNA size marker and lane 2: digested pTZ57R/T-InvG)
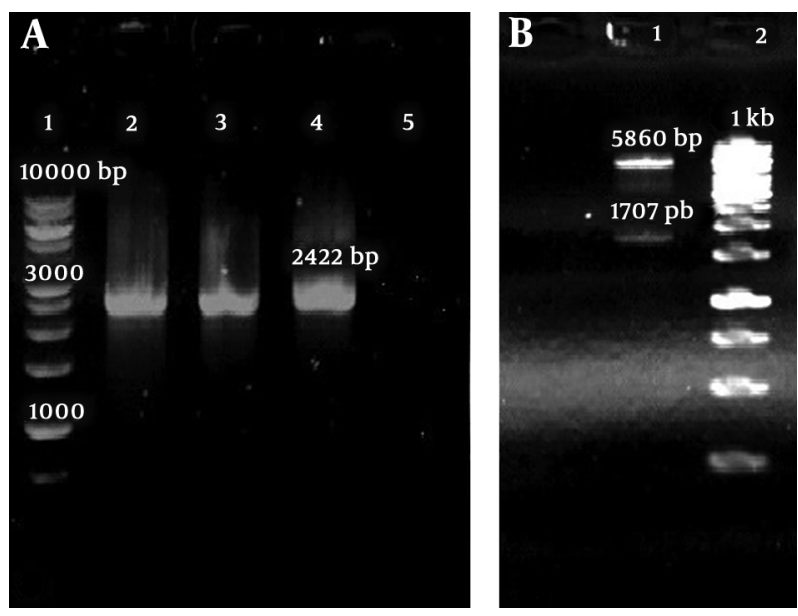

Figure 2. A, agarose gel electrophoresis of the InvG gene with PET T7 primers (lane 1: $1 \mathrm{~kb}$ DNA size marker, lane 2-4: InvG gene and lane 5: negative control). B, digestion of pET32a-InvG vector (lane 1: digested pET32a-InvG and lane 2: $1 \mathrm{~kb}$ DNA size marker)

\subsection{Specific Activity of $\operatorname{Ig} Y$}

The anti-InvG IgY activity was determined by iELISA. Mean ELISA titers of the anti-InvG IgY in two groups of laying hens are shown in Figure 5. There was a significant increase of the specific Anti-InvG IgY activity after the second week and the results showed specific antibody activity was gradually increased (P value $<0.05$ ). Significant differences were seen after the first immunization between the different weeks (P value $<0.05$ ). After the second and third injection, the anti-InvG IgY level was increased. As a result, significant differences were showed between the fourth and sixth weeks with the other weeks (P value < 0.05). Subsequently, the antibody levels reached the peak in 56 days after the first immunization. Also, significant differences were shown in the specific IgY activity between the third, fifth, and seventh week compared with other weeks $(\mathrm{P}<0.05)$. However, there was no significant difference between sixth and seventh weeks. No significant difference was revealed in the IgY activity in the last weeks of egg collection, indicating that the IgY level remained constant. In the control group, considerable change was not found.

\section{Discussion}

Salmonella disease has been identified as one of the main foodborne infections in humans and animals (14). It is essential to prevent Salmonella infection, not only to decrease productive losses in farm animals, but also to control its transmission to humans. Therefore, determining suitable methods of Salmonella surveillance will greatly assist the industry in recognition and control of Salmonella infections. In the recent years, there have been some researches of the resistance to commonly used antibiotics in different pathogens. As a result, serious concerns have arisen about the potential risk to human health from drug residues and the possible transfer of antibiotic resistant genes from animal to human microbiota (15). Passive immunization is an excellent method for control and therapy 

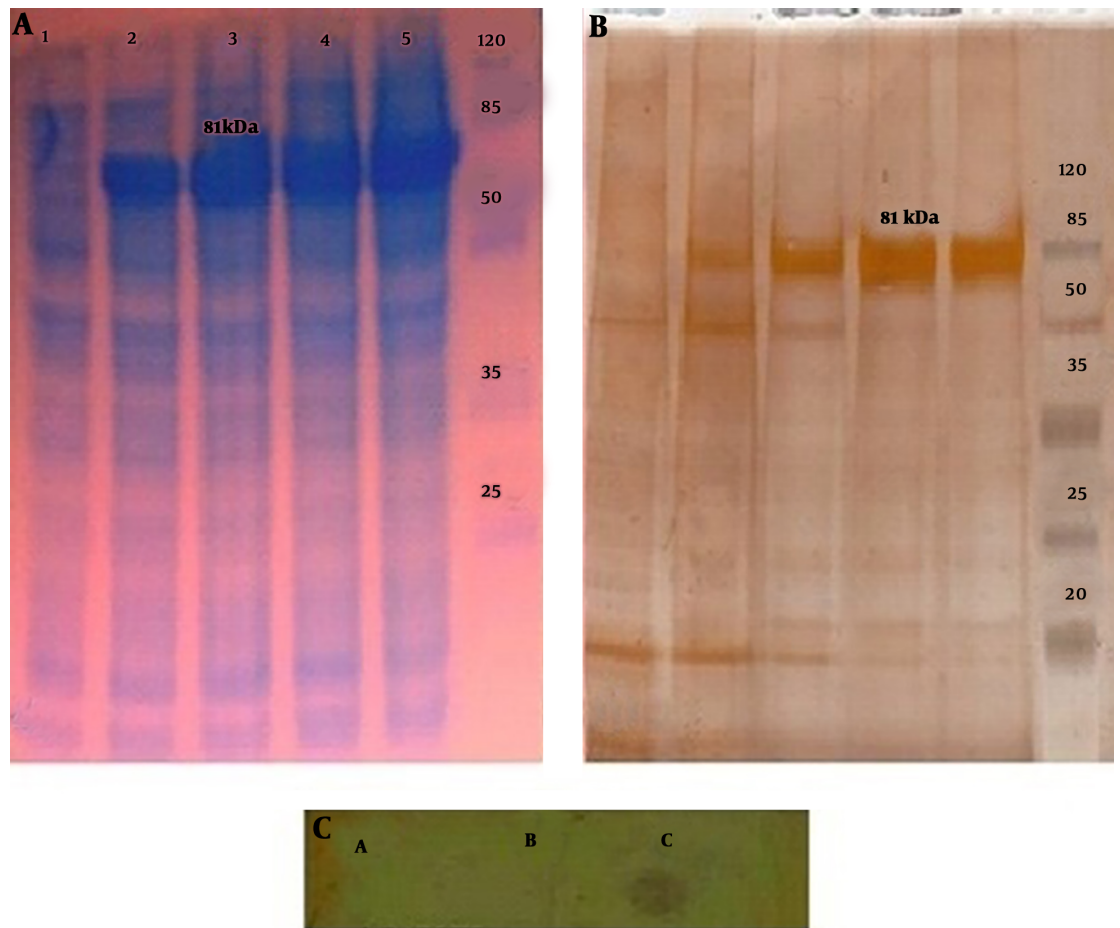

Figure 3. A, the results of SDS-PAGE. Lane 1: non-induced cells, lane 2 to 5: cells induced with IPTG at one, two, three, and four hours after induction, respectively, lane 6: protein size marker. B, Western-blot analysis of the InvG protein. C, Dot-blot analysis of the InvG protein [(A) PBS, (B) E. coli-pET32a-InvG and (C) E. coli-pET32a-InvG shows transformed bacteria induced with IPTG].
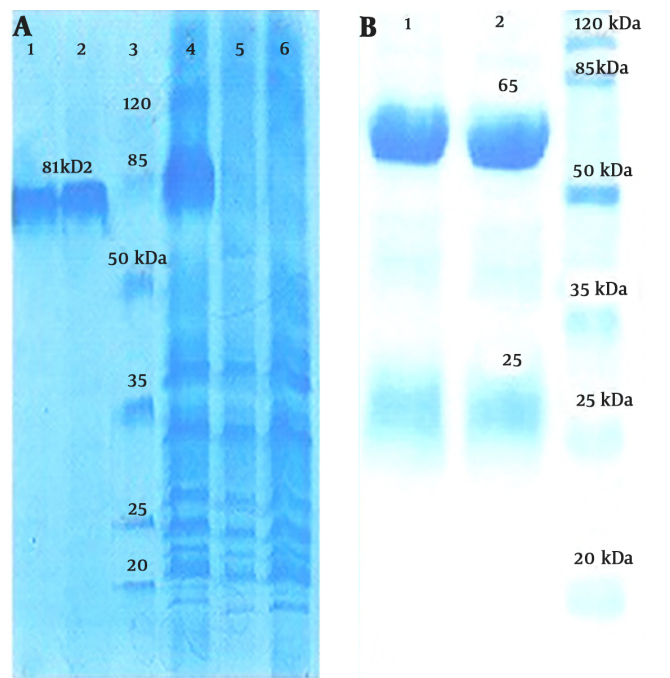

C

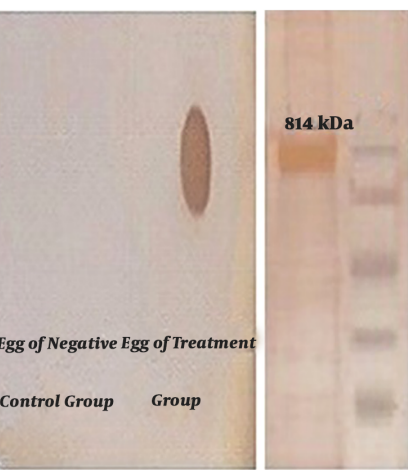

Figure 4. A, purification steps of InvG protein was electrophoresed on 12\% SDS-PAGE. Lane 11 to 2: the purified InvG protein, lane 3: protein size marker, lane 4 to 5: cleared cell lysate, lane 6: flow-though. B, SDS-PAGE analysis of the purified IgY antibody. C, Dot-blot and Western-blot of anti-InvG IgY.

of Salmonella enterica infections. Antibody Y is one of the candidates for oral administration approach. Use of IgY has advantages, such as high yield, convenience, and cost- effectiveness (11).

Several researches have indicated that specific IgY is greatly effective against Salmonella. Lee et al. (16) revealed 


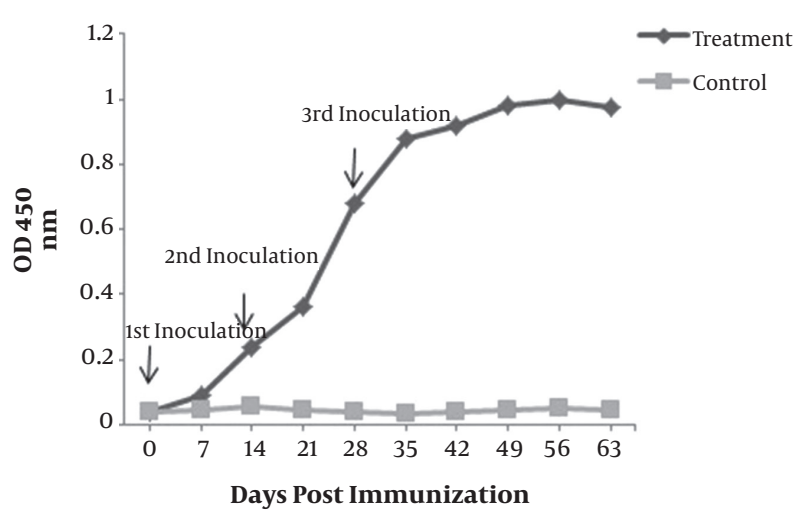

Figure 5. Mean ELISA titers in egg yolks of the hens immunized with the recombinant InvG protein in treatment and control groups

that specific IgY against Salmonella was able to prevent Salmonella growth. Also Salmonella-specific IgY was able to bind to the antigens expressed on the Salmonella surface, causing structural alterations in the bacterial surface. Gurtler et al. (17) evaluated the impact of oral administration of IgY on Salmonella contamination rate of eggs laid in hens. They suggested that IgY as a feed additive could be used to decrease the Salmonella contamination rate of hen's eggs. Chalghoumi et al. (18) immunized hens with outer membrane proteins of Salmonella enteritidis and Salmonella typhimurium. They produced specific IgY simultaneously against enteritidis and typhimurium in the same egg yolk. Gorbani et al. (19) produced specific IgY against Salmonella using Salmonella typhimurium-heatkilled whole cells and their results indicated that the egg yolks from hens immunized with Salmonella typhimurium protected mice from Salmonella. Li et al. (20) revealed that IgY modulated intestinal mucosal immune responses during Salmonella typhimurium infection.

The main strategy in this study was to clone and subclone InvG antigen of Salmonella typhimurium in expression plasmid and express this in E. coli. The pET32 as a recombinant vector was used in this study. The pET32 series is designed for cloning and high-level expression of peptide sequences fused with the $109 \mathrm{aa} \operatorname{Trx} \bullet \operatorname{Tag}^{\mathrm{TM}}$ thioredoxin protein. Cloning sites available for producing fusion proteins also contain cleavable His $\bullet \operatorname{Tag}^{\circledR}$ and $\mathrm{S} \bullet \mathrm{Tag}^{\mathrm{TM}}$ sequences for detection and purification of recombinant proteins (21). The InvG protein was inoculated to the laying hens to produce anti-InvG IgY. Anti-InvG IgY was detected in egg yolk of immunized hens. The findings of this research were in accordance with the findings of other researches that suggested hen immunization is a promising method for the production of antibodies $(22,23)$. In this study, antiInvG IgY was produced by immunizing the chicken with the InvG protein, which has never been reported before, according to the current study. The InvG antigen amount showed that it stimulated the immunological response. The results showed the InvG antigen could be identified specifically by anti-InvG IgY. The anti-InvG IgY was detected after the second week of post-injection in yolks. Fu et al. (24) explained that it takes two weeks for the production, transformation, and accumulation of specific IgY in the egg yolk. In the current study, antibody titer started to increase after the second week and reached the peak in 56 days after the first immunization.

These results were in agreement with the findings of the other researches that corroborated that E. coli expression system was able to express InvG protein of Salmonella $(25,26)$. Also, the results were in accordance with other results that showed specific anti-Salmonella IgY was produced using immunizing hens with Salmonella $(18,19)$.

\subsection{Conclusions}

The findings of the present research indicated that anti-InvG IgY could be utilized as one of the methods for immunotherapy to identify Salmonella infection. The antiInvG IgY could be applied in specific diagnostic method of Salmonella infection. Further experiments are recommended with different titers of IgY in order to evaluate the preventive effect of anti-InvG against Salmonella infection.

\section{Footnotes}

Authors' Contribution: Mohammad Hasan Jahandar contributed to design of the study and was involved in all steps of the experimental work, and performed the experiments. Mohammadreza Nassiri designed the project. Khadijeh Nasiri contributed in performed the experiments and manuscript preparation. Alireza Haghparast contributed in the project advisor.

Conflict of Interests: There were no conflicts of interests. Ethical Approval: Animal handling and experimental procedures were performed according to the guideline for Care and Use of Animals Laboratory published by the US National Institute of Health (NIH publication No. 85-23, revised 1996) and the current laws of Iran.

Funding/Support: This study was supported by Ferdowsi University of Mashhad, Mashhad, Iran.

\section{References}

1. Bopp CA, Brenner FW, Wells JG, Strockbine N. Escherichia, Shigella and Salmonella. In: Murray PR, Baron EJ, Pfaller MA, Tenover F, Yolken R, editors. Manual of clinical microbiology. 7th ed. Washington DC: ASM Press;1999. p. 459-74. 
2. Desin TS, Lam PK, Koch B, Mickael C, Berberov E, Wisner AL, et al. Salmonella enterica serovar enteritidis pathogenicity island 1 is not essential for but facilitates rapid systemic spread in chickens. Infect Immun. 2009;77(7):2866-75. doi: 10.1128/IAI.00039-09. [PubMed: 19364835]. [PubMed Central: PMC2708567].

3. Waterman SR, Holden DW. Functions and effectors of the Salmonella pathogenicity island 2 type III secretion system. Cell Microbiol. 2003;5(8):501-11. doi: 10.1046/j.1462-5822.2003.00294.x. [PubMed: 12864810].

4. Kubori T, Sukhan A, Aizawa SI, Galan JE. Molecular characterization and assembly of the needle complex of the Salmonella typhimurium type III protein secretion system. Proc Natl Acad Sci U S A. 2000;97(18):10225-30. doi: 10.1073/pnas.170128997. [PubMed: 10944190]. [PubMed Central: PMC27824].

5. Hapfelmeier S, Ehrbar K, Stecher B, Barthel M, Kremer M, Hardt WD. Role of the Salmonella pathogenicity island 1 effector proteins SipA, SopB, SopE, and SopE2 in Salmonella enterica subspecies 1 serovar typhimurium colitis in streptomycin-pretreated mice. In fect Immun. 2004;72(2):795-809. doi: 10.1128/IAI.72.2.795-809.2004. [PubMed: 14742523]. [PubMed Central: PMC321604].

6. Kaniga K, Bossio JC, Galan JE. The Salmonella typhimurium invasion genes invF and invG encode homologues of the AraC and PulD family of proteins. Mol Microbiol. 1994;13(4):555-68. doi: 10.1111/j.13652958.1994.tb00450.x. [PubMed: 7997169].

7. Smith DJ, King WF, Godiska R. Passive transfer of immunoglobulin $\mathrm{Y}$ antibody to Streptococcus mutans glucan binding protein $\mathrm{B}$ can confer protection against experimental dental caries. Infect Immun. 2001;69(5):3135-42. doi: 10.1128/IAI.69.5.3135-3142.2001. [PubMed: 11292733]. [PubMed Central: PMC98269].

8. Kobayashi C, Yokoyama H, Nguyen SV, Kodama Y, Kimata T, Izeki M. Effect of egg yolk antibody on experimental Cryptosporidium parvum infection in scid mice. Vaccine. 2004;23(2):232-5. doi: 10.1016/j.vaccine.2004.05.034. [PubMed:15531042]

9. Mine Y, Kovacs-Nolan J. Chicken egg yolk antibodies as therapeutics in enteric infectious disease: A review. J Med Food. 2002;5(3):159-69. doi: 10.1089/10966200260398198. [PubMed:12495588].

10. Nasiri K, Nassiri MR, Tahmoorespur M, Haghparast A,Zibaee S. Production and characterization of egg yolk antibody (IgY) against recombinant VP8-S2 antigen. Pol J Vet Sci. 2016;19(2):271-9. doi: 10.1515/pjvs2016-0034. [PubMed: 27487500].

11. Xu Y, Li X, Jin L, Zhen Y, Lu Y, Li S, et al. Application of chicken egg yolk immunoglobulins in the control of terrestrial and aquatic animal diseases: A review. Biotechnol Adv. 2011;29(6):860-8. doi: 10.1016/j.biotechadv.2011.07.003. [PubMed: 21787857].

12. Bradford MM. A rapid and sensitive method for the quantitation of microgram quantities of protein utilizing the principle of protein-dye binding. Anal Biochem. 1976;72:248-54. doi: 10.1016/00032697(76)90527-3. [PubMed: 942051].

13. Pauly D, Chacana PA, Calzado EG, Brembs B, Schade R. IgY technology: Extraction of chicken antibodies from egg yolk by polyethylene glycol (PEG) precipitation. J Vis Exp. 2011;(51). doi: 10.3791/3084. [PubMed: 21559009]. [PubMed Central: PMC3197133].
14. Mead PS, Slutsker L, Dietz V, McCaig LF, Bresee JS, Shapiro C, et al. Food-related illness and death in the United States. Emerg Infect Dis. 1999;5(5):607-25. doi: 10.3201/eid0505.990502. [PubMed: 10511517]. [PubMed Central: PMC2627714].

15. Castanon JI. History of the use of antibiotic as growth promoters in European poultry feeds. Poult Sci. 2007;86(11):2466-71. doi: 10.3382/ps.2007-00249. [PubMed: 17954599].

16. Lee EN, Sunwoo HH, Menninen K, Sim IS. In vitro studies of chicken egg yolk antibody (IgY) against Salmonella enteritidis and Salmonella typhimurium. Poult Sci. 2002;81(5):632-41. doi: 10.1093/ps/81.5.632. [PubMed: 12033412].

17. Gurtler M, Methner U, Kobilke H, Fehlhaber K. Effect of orally administered egg yolk antibodies on Salmonella enteritidis contamination of hen's eggs. J Vet Med B Infect Dis Vet Public Health. 2004;51(3):129-34. doi: 10.1111/j.1439-0450.2004.00739.x. [PubMed:15107039].

18. Chalghoumi R, Thewis A, Portetelle D, Beckers Y. Production of hen egg yolk immunoglobulins simultaneously directed against Salmonella enteritidis and Salmonella typhimurium in the same egg yolk. Poult Sci.2008;87(1):32-40. doi:10.3382/ps.2007-00252. [PubMed: 18079447].

19. Gorbani N, Saadati M, Bahmani MK, Doroudian M. Production of hen egg yolk antibody against zoonotic disease (salmonellosis) and passive immunization in mice. Adv Environ Biol. 2011;5(12):3710-5.

20. Li X, Yao Y, Wang X, Zhen Y, Thacker PA, Wang L, et al. Chicken egg yolk antibodies (IgY) modulate the intestinal mucosal immune response in a mouse model of Salmonella typhimurium infection. Int Immunopharmacol. 2016;36:305-14. doi: 10.1016/j.intimp.2016.04.036. [PubMed: 27214338].

21. LaVallie ER, DiBlasio EA, Kovacic S, Grant KL, Schendel PF, McCoy JM. A thioredoxin gene fusion expression system that circumvents inclusion body formation in the E. coli cytoplasm. Biotechnology (N Y). 1993;11(2):187-93. [PubMed: 7763371]

22. Han S, Zhang X, Zhao J. Production of egg yolk antibody (IgY) against recombinant canine parvovirus VP2 protein. Acta Sci Veterinariae. $2012 ; 40(2)$.

23. Nasiri K, Zibaee S, Nassiri M, Tahmoorespur M, Haghparast A. Production of specific IgY antibody to the recombinant FanC protein produced in Escherichia coli. Iran J Basic Med Sci. 2016;19(8):883-9. [PubMed: 27746871]. [PubMed Central: PMC5048125].

24. Fu CY, Huang H, Wang XM, Liu YG, Wang ZG, Cui SJ, et al. Preparation and evaluation of anti-SARS coronavirus IgY from yolks of immunized SPF chickens. J Virol Methods. 2006;133(1):112-5. doi: 10.1016/j.jviromet.2005.10.027. [PubMed: 16325277].

25. Crago AM, Koronakis V. Salmonella InvG forms a ring-like multimer that requires the InvH lipoprotein for outer membrane localization. Mol Microbiol. 1998;30(1):47-56. doi: 10.1046/j.1365-2958.1998.01036.x. [PubMed: 9786184].

26. Sanowar S, Singh P, Pfuetzner RA, Andre I, Zheng H, Spreter T, et al. Interactions of the transmembrane polymeric rings of the Salmonella enterica serovar typhimurium type III secretion system. MBio. 2010;1(3). doi: 10.1128/mBio.00158-10. [PubMed: 20824104]. [PubMed Central: PMC2932509]. 